\title{
Relationship between balance and physical activity measured by an activity monitor in elderly COPD patients
}

\author{
Masahiro Iwakura ${ }^{1,2}$ \\ Kazuki Okura² \\ Kazuyuki Shibata ${ }^{1,2}$ \\ Atsuyoshi Kawagoshi \\ Keiyu Sugawara ${ }^{2}$ \\ Hitomi Takahashi ${ }^{2}$ \\ Takanobu Shioya'
}

'Department of Rehabilitation, Akita City Hospital, ${ }^{2}$ Department of Physical Therapy, Akita University Graduate School of Health Sciences, Akita, Japan
This article was published in the following Dove Press journal: International Journal of COPD

I July 2016

Number of times this article has been viewed

Background: Little is known regarding the relationship between balance impairments and physical activity in COPD. There has been no study investigating the relationship between balance and objectively measured physical activity. Here we investigated the association between balance and physical activity measured by an activity monitor in elderly COPD patients.

Materials and methods: Twenty-two outpatients with COPD (mean age, $72 \pm 7$ years; forced expiratory volume in 1 second, $53 \% \pm 21 \%$ predicted) and 13 age-matched healthy control subjects (mean age, $72 \pm 6$ years) participated in the study. We assessed all 35 subjects' balance (one-leg standing test [OLST] times, Short Physical Performance Battery total scores, standing balance test scores, $4 \mathrm{~m}$ gait speed, and five-times sit-to-stand test [5STST]) and physical activity (daily steps and time spent in moderate-to-vigorous physical activity per day [MV-PA]). Possible confounders were assessed in the COPD group. The between-group differences in balance test scores and physical activity were analyzed. A correlation analysis and multivariate regression analysis were conducted in the COPD group.

Results: The COPD patients exhibited significant reductions in OLST times $(P=0.033)$, Short Physical Performance Battery scores $(P=0.013), 4$ m gait speed $(P<0.001)$, five-times sit-tostand times $(P=0.002)$, daily steps $(P=0.003)$, and MV-PA $(P=0.022)$ compared to the controls; the exception was the standing balance test scores. The correlation and multivariate regression analyses revealed significant independent associations between OLST times and daily steps $(P<0.001)$ and between OLST times and MV-PA $(P=0.014)$ in the COPD group after adjusting for possible confounding factors.

Conclusion: Impairments in balance and reductions in physical activity were observed in the COPD group. Deficits in balance are independently associated with physical inactivity.

Keywords: COPD, balance impairments, physical inactivity, activity monitor, pulmonary rehabilitation

\section{Introduction}

Physical activity levels are significantly decreased in individuals with COPD compared to age-matched healthy controls. ${ }^{1-3}$ Physical inactivity has adverse effects on lung function, muscle mass, exercise tolerance, and mortality. ${ }^{4-6}$ Many researchers have investigated the relationships between physical activity and clinical characteristics to reveal the mechanisms in understanding physical inactivity in COPD. For instance, pulmonary function, dyspnea, body composition, extrapulmonary function, and health status have been shown to have significant associations with physical activity in COPD. ${ }^{7,8}$

The latest systematic review of the determinants of physical activity in COPD indicated that balance might also be associated with physical activity in COPD. ${ }^{8}$
Correspondence: Masahiro Iwakura Department of Rehabilitation, Akita City Hospital, 4-30 Kawamoto Matsuoka-cho, Akita City, Akita 0100933, Japan

Tel +8I I8 823 4I 7 |

Fax +81188667026

Email m.iwa.phys.ther@gmail.com 
The association between balance and physical activity in COPD has not yet been established, however. Only two studies examined the relationship between balance and self-reported physical activity in COPD., ${ }^{9,10}$ In addition, the accuracy of questionnaires that have been used for assessing physical activity is lower than that of objective measurement tools, mainly due to recall bias. ${ }^{11}$ The relationship between balance and physical activity should thus be investigated by using objective measurement tools for assessing physical activity.

Balance impairments have been commonly recognized in COPD. ${ }^{9,10,12}$ Beauchamp et al investigated balance impairments in COPD using the Balance Evaluation Systems Test. ${ }^{9}$ This test evaluates six subcomponents of balance: biomechanical constraints, stability limits/verticality, anticipatory adjustments/transitions, postural responses, sensory orientation, and stability in gait. In the Beauchamp study, COPD patients had deficits in all six subcomponents of the test compared to healthy controls, with marked deficits in biomechanical constraints, anticipatory adjustments/transitions, and stability in gait. ${ }^{9}$ Although there is insufficient evidence to conclude that there is an association between balance and physical activity, subcomponents of balance such as transitions and gait are essential for independent living and are main components of physical activity..$^{13,14}$

The aim of our present study, therefore, was to investigate the association between balance impairments and physical activity as measured by an activity monitor in COPD patients. We hypothesized that impaired balance would be associated with physical inactivity in COPD.

\section{Materials and methods Subjects}

Twenty-two stable elderly COPD patients (all male; age $71.6 \pm 6.9$ years) who had undergone pulmonary rehabilitation in our hospital were enrolled in this study. All 22 patients met the following criteria: diagnosis of COPD according to international guidelines ${ }^{15}$ and provided written informed consent. The exclusion criteria were as follows: an inability to communicate, use of medication(s) that may increase the risk of falls, and neurologic or musculoskeletal conditions that limit mobility. Thirteen healthy age-matched male control subjects with normal spirometry (forced expiratory volume in 1 second $\left[\mathrm{FEV}_{1}\right] \geq 80 \%$ predicted, $\mathrm{FEV}_{1}$ /forced vital capacity $\geq 0.7$ ) were recruited at a local community center. The exclusion criterion was absence of any health problems that may have impaired mobility or postural control.

\section{Study design}

A cross-sectional study design was used. All subjects underwent clinical balance tests and physical activity measures. The COPD patients also performed physical function tests and completed two questionnaires. Pulmonary function data were retrieved from the clinical records of the COPD patients and obtained through simple spirometry in the healthy controls. The pulmonary function data of the COPD patients were measured within the 3 months before the balance tests and physical activity measures. This study was reviewed and approved by the Ethics Committee of Akita City Hospital, 2015 (accepted No 19), and carried out in conformity with the Declaration of Helsinki.

\section{Clinical balance measures}

The clinical balance tests included the one-leg standing test (OLST) and the Short Physical Performance Battery (SPPB) to assess four subcomponents of balance: anticipatory adjustments, standing balance, gait stability, and transitions.

The OLST was performed as described by Michikawa et al. ${ }^{16}$ The length of time that each subject was able to stand on one leg without any support was measured. The test was over after 60 seconds had elapsed, when the stance foot shifted, or when the lifted foot was replaced on a board supplied for the test. The subjects were given two trials unless they were able to complete 60 seconds on the first trial. The better of the two trial times was recorded.

The SPPB consists of three components: a standing balance test, a $4 \mathrm{~m}$ gait test (4MGT), and a five-times sitto-stand test (5STST). ${ }^{17}$ The standing balance test evaluates the subject's ability to stand with the feet together side-byside, in a semi-tandem position and in a tandem position for 10 seconds. The 4MGT evaluates the time that a subject requires to walk $4 \mathrm{~m}$. The $5 \mathrm{STST}$ evaluates the time that a subject requires to rise from a chair and return to the seated position five times. ${ }^{17}$ The three SPPB components were scored from 0 to 4 , with higher scores indicating better balance. The SPPB total scores, standing balance test scores, $4 \mathrm{~m}$ gait speed (4MGS), and 5STST times were calculated. The reliability of the 4MGT and 5STST is well established in patients with COPD. ${ }^{18}$

In the present study, we used the OLST times as the measure of anticipatory adjustment, ${ }^{9}$ the standing balance test scores as the measure of standing balance, ${ }^{17}$ the $4 \mathrm{MGS}$ results as the measure of gait stability, ${ }^{9,19}$ and the 5STST times as the measure of transitions. ${ }^{9,20}$ The SPPB total scores were also used to assess the subjects' balance abilities. 


\section{Objectively measured physical activity}

Each subject's physical activity was objectively measured using an accelerometer-based activity monitor (Lifecorder ${ }^{\mathrm{TM}}$, Suzuken Co., Nagoya, Japan). The activity monitor $\left(625 \times 465 \times 260 \mathrm{~mm}^{3}, 40 \mathrm{~g}\right)$ was firmly attached to a belt or the waistband of the subject's clothing on at least five weekdays. ${ }^{11}$ The number of the subject's average daily steps and the time spent in moderate-to-vigorous physical activity per day (MV-PA) were calculated as their physical activity levels. Daily steps may include activities such as slow and fast walking, household work, or shopping. ${ }^{13,14}$ Moderate-to-vigorous physical activity, equivalent to $>3.0$ metabolic equivalents, may include activities such as brisk walking, climbing stairs, aerobics, or heavy household work. ${ }^{21}$ The validity and reliability of this method have been demonstrated. ${ }^{22,23}$

\section{Possible confounders}

We measured pulmonary function, nutritional status, dyspnea, quadriceps muscle strength, functional exercise capacity, and health-related quality of life as possible confounders in the COPD group. These confounders may affect balance and physical activity in COPD..$^{8,12}$

For the pulmonary function, $\mathrm{FEV}_{1}$ was measured using a spirometer (Chestgraph Jr. HI-101, Chest M.I., Inc., Tokyo, Japan) by well-trained physical therapists following the American Thoracic Society (ATS) guideline. ${ }^{24}$ The $\% \mathrm{FEV}_{1}$ was calculated following the ATS guideline ${ }^{24}$ and the reference values provided by Berglund et al. ${ }^{25}$ The subjects' body mass index was measured as an indicator of their nutritional status. The degree of dyspnea was measured using the modified Medical Research Council (MMRC) dyspnea scale. ${ }^{26}$

For the quadriceps muscle strength data, we measured each subject's quadriceps isometric maximum voluntary contraction normalized to body weight (QMVC) using the Hydromusculator GT-160 (OG Giken Co., Okayama, Tokyo) in accordance with the method described by Sugawara et al. ${ }^{27}$ The 6-minute walk distance (6MWD) was measured as an indicator of functional exercise capacity. The subjects performed the 6MWD test according to the European Respiratory Society/ATS technical standard. ${ }^{28}$ For the healthrelated quality of life data, each subject completed the COPD assessment test, and the total score was calculated. ${ }^{29}$

\section{Statistical analysis}

The statistical analyses were performed using SPSS software (Version 22.0 for Windows; IBM Corporation, Armonk, NY, USA). The assumption of normality was assessed by graphical and statistical methods. For all analyses, a $P$-value $<0.05$ was considered significant. Independent samples $t$-tests were used to determine between-group differences for continuous variables, and the Mann-Whitney $U$-test was used for nonparametric and discrete variables. Pearson correlations and Spearman rank correlations were used to determine the relationships among balance, physical activity, and the possible confounders in the COPD patients.

We performed forced-entry multivariate linear regression analyses to determine the variables independently associated with balance and physical activity in the COPD patients. Analysis 1 was performed to determine the variables influencing balance. One balance measure with the strongest correlations to daily steps and MV-PA was used as the dependent variable. One physical activity outcome with the strongest correlations to the balance measure and possible confounders that correlated with the balance measure were used as predictors.

Analysis 2 was performed to explore the variables influencing daily steps. The number of daily steps was used as the dependent variable. One balance measure with the strongest correlation to daily steps and possible confounders that correlated to daily steps were used as the predictors.

Analysis 3 was performed to detect the variables influencing the MV-PA times. The MV-PA time was used as the dependent variable. One balance measure with the strongest correlation to MV-PA and possible confounders that correlated to MV-PA were used as the predictors.

The three analyses were divided into two steps to adjust for age and possible confounders, in accordance with the method described by Beauchamp et al. ${ }^{9}$ In the first step, age was included in the models independently of statistical significance. In the second step, the respective predictors were included in the models.

Power analysis was performed with the program $\mathrm{G}^{*}$ Power $^{30}$ for a multivariate regression with five predictors, an $\alpha$ of 0.05 , and power of 0.80 . A sample size of 43 was required to detect a large $\left(\right.$ Cohen $\left.f^{2}=0.35\right)$ effect size.

\section{Results}

The subjects' characteristics are given in Table 1. The COPD group showed significant expiratory airflow limitation consistent with GOLD (Global Initiative for Chronic Obstructive Pulmonary Disease) stage II disease. ${ }^{15}$ The healthy control subjects had normal spirometry data and were well matched for age and body composition.

The results from the clinical balance tests, the physical activity measures, and the possible confounders are shown 
Table I Characteristics of the COPD patients and healthy controls

\begin{tabular}{llll}
\hline Characteristics & COPD $(\mathbf{n}=\mathbf{2 2})$ & Control $(\mathbf{n}=\mathbf{I} \mathbf{3})$ & $\boldsymbol{P}$-value \\
\hline Age $($ years $)$ & $71.6(6.9)$ & $71.5(5.6)$ & 0.982 \\
Height $(\mathrm{m})$ & $1.65(0.05)$ & $1.65(0.06)$ & 0.906 \\
Body weight $(\mathrm{kg})$ & $60.0(6.7)$ & $62.2(9.3)$ & 0.432 \\
BMI $\left(\mathrm{kg} \cdot \mathrm{m}^{-2}\right)$ & $22.1(2.9)$ & $22.7(2.5)$ & 0.530 \\
FVC (L) & $2.85(0.95)$ & $2.99(0.88)$ & 0.698 \\
FEV $(\%$ predicted) & $52.8(20.6)^{*}$ & $94.7(26.7)$ & $<0.00 \mathrm{I}$ \\
FEV $_{1} /$ FVC (\%) & $46.8(14.0)^{*}$ & $86.5(1 \mathrm{I} .2)$ & $<0.00 \mathrm{I}$ \\
\hline
\end{tabular}

Notes: Data are mean (SD) unless indicated otherwise; *indicates differences are significant.

Abbreviations: BMI, body mass index; FVC, forced vital capacity; FEV , forced expiratory volume in I second; SD, standard deviation.

in Table 2. The COPD patients demonstrated significantly shorter OLST times $(P=0.033)$, lower SPPB total scores $(P=0.013)$, slower 4MGS $(P<0.001)$, and slower 5STST times $(P=0.002)$. In contrast, there were no significant differences between the COPD and control groups in the standing balance test scores. Significantly reduced number of daily steps $(P=0.003)$ and MV-PA times $(P=0.014)$ were evident in the COPD patients compared to the controls.

The results of the correlation analysis are given in Table 3. The OLST times were significantly associated with daily steps $(P<0.001)$, MV-PA $(P=0.001)$, QMVC $(P=0.017)$, and 6MWD $(P=0.016)$ (Figure 1A). The SPPB total scores were significantly associated with daily steps $(P=0.006)$, MV-PA $(P=0.002)$, MMRC $(P=0.020)$, and 6MWD $(P=0.004)$ (Figure 1B). The 4MGS was significantly correlated with MMRC $(P=0.015)$, QMVC $(P=0.010)$, and 6MWD $(P=0.001)$. Daily steps were also significantly associated with $6 \operatorname{MWD}(P=0.001), \operatorname{MMRC}(P=0.002)$, and QMVC $(P=0.009)$ (Figure 2A). MV-PA was also significantly associated with 6MWD $(P=0.001)$ and MMRC $(P=0.007)$ (Figure 2B).
In the three multivariate regression analyses, the OLST times were used as an indicator of balance because the OLST times had the strongest correlations to the daily steps and MV-PA among the five balance measures. Table 4 provides the results of Analysis 1 using the OLST times as the dependent variable and daily steps, QMVC, and 6MWD as predictors. Analysis 1 including age, daily steps, 6MWD, and QMVC explained $70 \%$ of the variance in the OLST times $(P<0.001)$. Only daily steps were independently associated with OLST times $(P<0.001)$.

Table 5 summarizes the results of Analysis 2 using daily steps as the dependent variable and the OLST times, MMRC, QMVC, and 6MWD as predictors. Analysis 2 including age, the OLST times, 6MWD, QMVC, and MMRC explained $73 \%$ of the variance in the daily steps $(P<0.001)$. Only the OLST times were independently associated with daily steps $(P<0.001)$. Table 6 shows the results of Analysis 3 using the MV-PA as the dependent variable and the OLST times, 6MWD, and MMRC as predictors. Analysis 3 including age, the OLST times, 6MWD, and MMRC explained 52\% of the variance in the MV-PA $(P=0.002)$. The OLST times $(P=0.014)$ and 6MWD $(P=0.024)$ were independently associated with MV-PA.

\section{Discussion}

The present study is the first to demonstrate an association between balance and objectively measured physical activity. As noted in the section "Introduction", only two studies have investigated the relationship between balance and self-reported physical activity in COPD., ${ }^{9} 10$ Our present work extends these observations by using objective measurement tools for assessing physical activity. Three novel findings regarding COPD patients were obtained in this

Table 2 Balance, physical activity, and the possible confounders in COPD patients and controls

\begin{tabular}{|c|c|c|c|c|c|}
\hline Outcome measures & COPD $(n=22)$ & Healthy control $(n=13)$ & Mean difference & $95 \% \mathrm{Cl}$ & $P$-value \\
\hline OLST (seconds) & $30.4(21.5)^{*}$ & $46.4(18.6)$ & -16.0 & $-30.5,-1.4$ & 0.033 \\
\hline SPPB total (point) & $10.7(\mathrm{I} .7)^{*}$ & $12(12.12)$ & - & - & 0.013 \\
\hline Standing balance test (point) & $4(4.4)$ & $4(4.4)$ & - & - & - \\
\hline 4MGS $\left(\mathrm{m} \cdot \mathrm{s}^{-1}\right)$ & $0.94(0.20)^{*}$ & $\mathrm{I} .42(0.30)$ & -0.48 & $-0.65,-0.30$ & $<0.001$ \\
\hline 5STST (seconds) & $11.05(3.19)^{*}$ & $7.75(1.77)$ & 3.30 & $1.3,5.3$ & 0.002 \\
\hline Daily steps (steps per day) & $4,546(2,992)^{*}$ & $8,7 \mid 3(3,480)$ & $-4,167$ & $-6,808,-1,527$ & 0.003 \\
\hline MV-PA (min. day $\left.{ }^{-1}\right)$ & $13.9(\mid 4.0)^{*}$ & $27.4(19.1)$ & -13.5 & $-24.9,-2.1$ & 0.022 \\
\hline MMRC (points) & $\mathrm{I} .8(0.7)$ & - & - & - & - \\
\hline QMVC (kg/kg) & $0.68(0.22)$ & - & - & - & - \\
\hline 6MWD (m) & $423.7(138.3)$ & - & - & - & - \\
\hline CAT (point) & |4.I (4.7) & - & - & - & - \\
\hline
\end{tabular}

Notes: Data are mean (SD) or median (25 percentile, 75 percentile); *differences are significant.

Abbreviations: OLST, one-leg standing test; SPPB, Short Physical Performance Battery; 4MGS, $4 \mathrm{~m}$ gait speed; 5STST, five-times sit-to-stand-test; MV-PA, time spent in moderate-to-vigorous physical activity per day; MMRC, modified Medical Research Council; QVMC, quadriceps isometric maximum voluntary contraction normalized to body weight; 6MWD, 6-minute walk distance; CAT, COPD assessment test; $\mathrm{Cl}$, confidence interval; SD, standard deviation. 
Table 3 Correlations among balance, physical activity, and the possible confounders in the COPD patients $(n=22)$

\begin{tabular}{|c|c|c|c|c|c|c|c|c|}
\hline Outcome measures & Daily steps & MV-PA & BMI & FEV $_{1}$ & MMRC & QMVC & 6MWD & CAT \\
\hline \multicolumn{9}{|l|}{ Balance } \\
\hline OLST & $0.82 I^{*}$ & $0.645^{*}$ & 0.217 & -0.285 & -0.462 & $0.504 *$ & $0.509 *$ & -0.043 \\
\hline SPPB total & $0.563^{*}$ & $0.621^{*}$ & 0.056 & 0.018 & $-0.504^{*}$ & $0.34 I$ & $0.514 *$ & 0.288 \\
\hline 4MGS & 0.364 & 0.260 & -0.137 & 0.399 & $-0.523^{*}$ & $0.534^{*}$ & $0.642^{*}$ & 0.026 \\
\hline 5STST & -0.299 & -0.384 & -0.154 & -0.002 & 0.424 & -0.285 & -0.406 & -0.291 \\
\hline \multicolumn{9}{|l|}{ Physical activity } \\
\hline Daily steps & 1.00 & $0.892^{*}$ & 0.190 & -0.060 & $-0.636^{*}$ & $0.546 *$ & $0.660 *$ & -0.120 \\
\hline MV-PA & $0.892^{*}$ & 1.00 & 0.257 & 0.165 & $-0.558 *$ & 0.370 & $0.654^{*}$ & -0.036 \\
\hline
\end{tabular}

Notes: This table shows correlations among balance and physical activity and the possible confounders in the COPD patients ( $\mathrm{n}=22$ ); ${ }^{*}$ correlations are significant.

Abbreviations: OLST, one-leg standing test; SPPB, Short Physical Performance Battery; 4MGS, $4 \mathrm{~m}$ gait speed; 5STST, five-times sit-to-stand test; MV-PA, time spent in moderate-to-vigorous physical activity per day; BMI, body mass index; FEV , forced expiratory volume in I second; MMRC, modified Medical Research Council; QVMC, quadriceps isometric maximum voluntary contraction normalized to body weight; 6MWD, 6-minute walk distance; CAT, COPD assessment test.
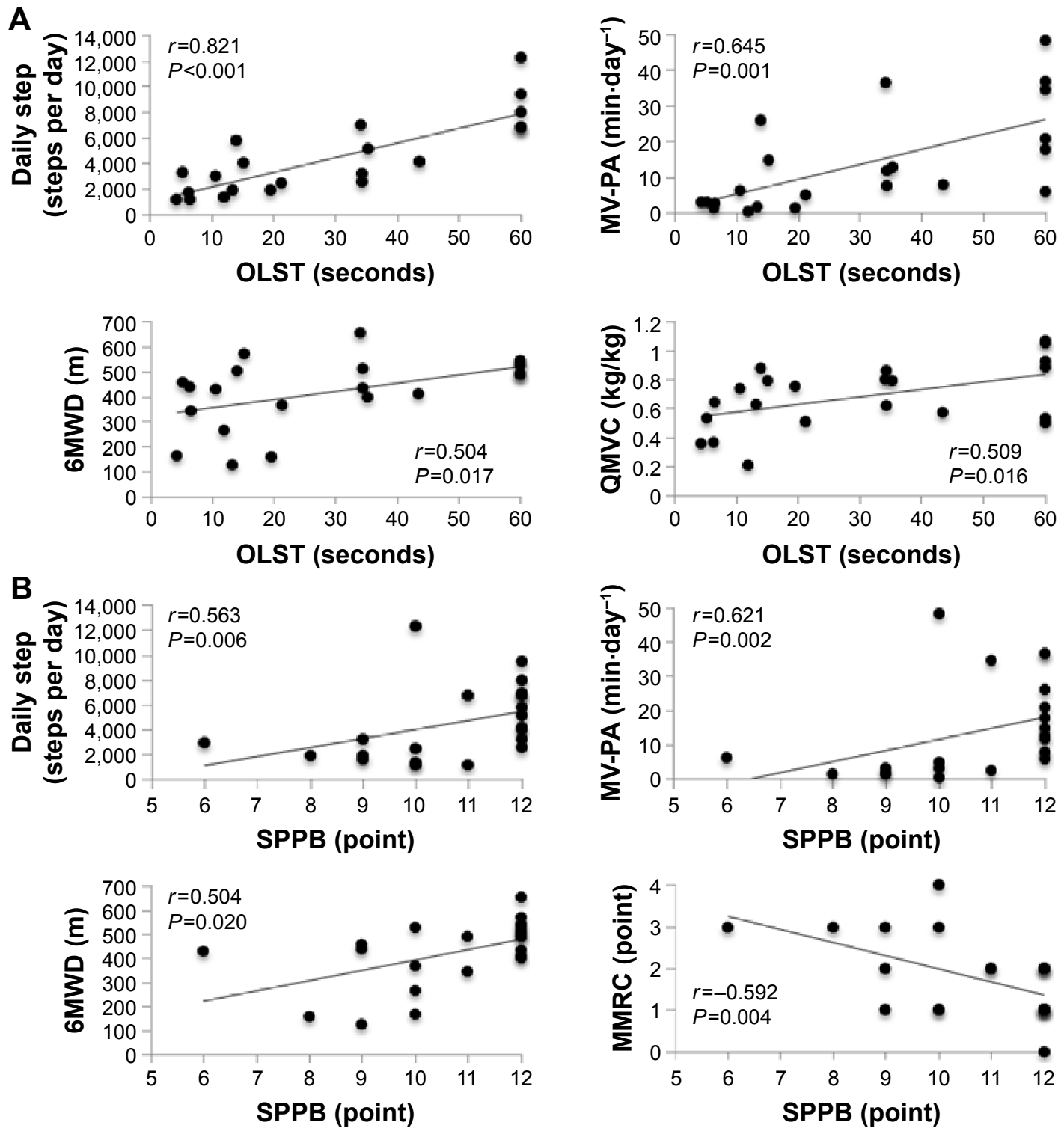

Figure I Correlations between balance measures and physical activity and possible confounders in subjects with COPD ( $\mathrm{n}=22$ ).

Notes: (A) OLST and (B) SPPB.

Abbreviations: OLST, one-legged standing test; SPPB, Short Physical Performance Battery; MV-PA, time spent in moderate-to-vigorous physical activity per day; 6MWD, 6-minute walk distance; QMVC, quadriceps isometric maximum voluntary contraction normalized to body weight; MMRC, modified Medical Research Council. 

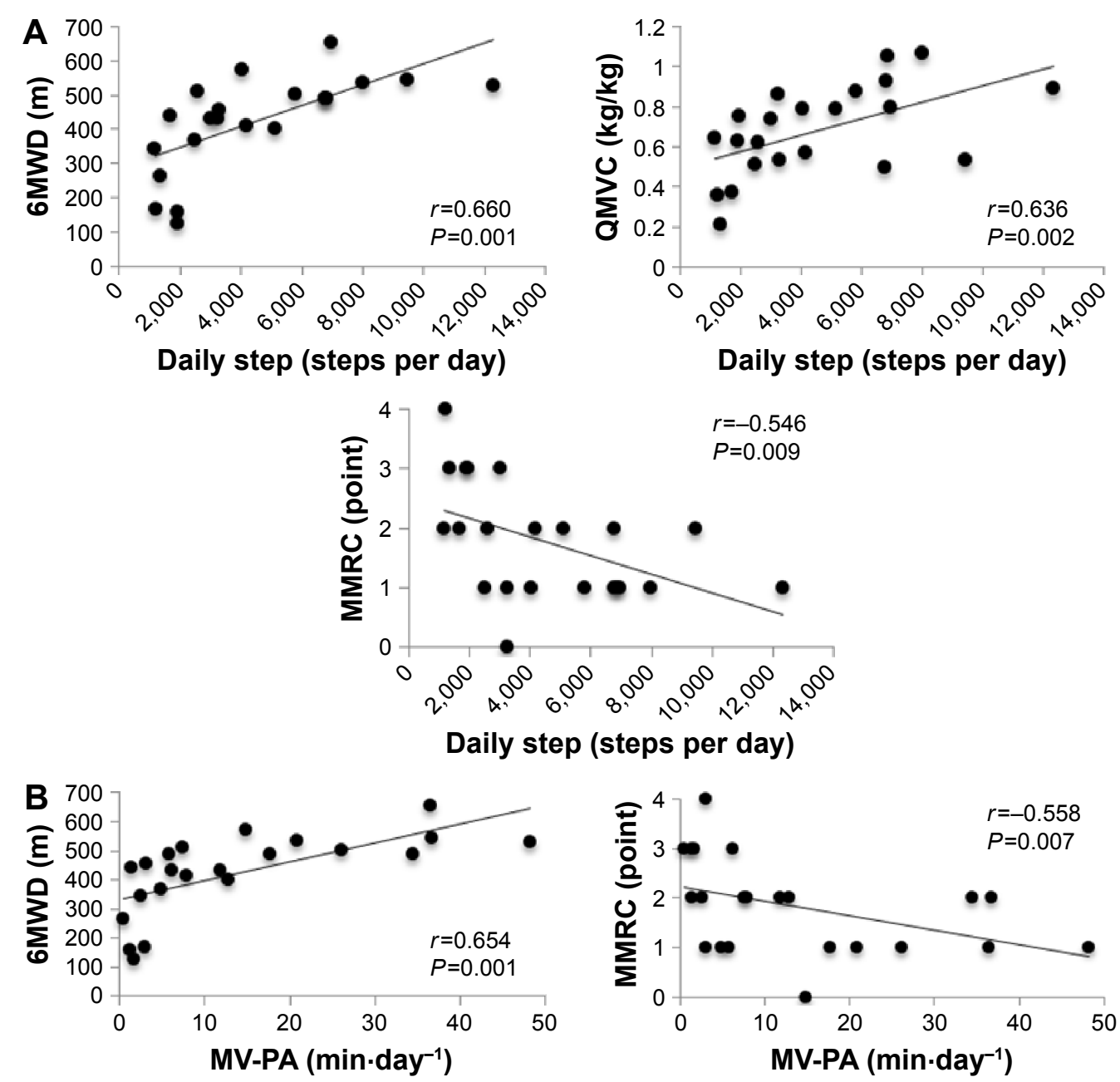

Figure 2 Correlations between physical activity and possible confounders in subjects with COPD ( $\mathrm{n}=22$ ).

Notes: (A) Daily step and (B) MV-PA.

Abbreviations: MV-PA, time spent in moderate-to-vigorous physical activity per day; 6MWD, 6-minute walk distance; QMVC, quadriceps isometric maximum voluntary contraction normalized to body weight; MMRC, modified Medical Research Council.

study. First, their physical activity (daily steps and MV-PA), exercise capacity, lower muscle strength, and dyspnea were associated with their balance. Second, the patients' balance, exercise capacity, lower muscle strength, and dyspnea were correlated with daily steps, and balance, exercise capacity,

Table 4 The independent variables influencing the OLST times in the COPD patients $(n=22)$

\begin{tabular}{llll}
\hline Variables & $\boldsymbol{\beta}$ & $\boldsymbol{t}$-value & $\boldsymbol{P}$-value \\
\hline Daily steps & 0.819 & 4.799 & $<0.001$ \\
6MWD & 0.209 & 1.231 & 0.253 \\
QMVC & 0.064 & 0.446 & 0.661 \\
Adjusted $R^{2}$ & 0.704 & & \\
\hline
\end{tabular}

Note: The data are the results of a multivariable regression Analysis I using the OLST times as the dependent variable and daily steps, QMVC, and 6MWD as predictors.

Abbreviations: OLST, one-leg standing test; $\beta$, standardized partial regression coefficient; adjusted $R^{2}$, adjusted coefficient of determination; 6MWD, 6-minute walk distance; QMVC, quadriceps isometric maximum voluntary contraction normalized to body weight. and dyspnea were associated with the MV-PA. Third, the COPD patients' balance was independently associated with the number of their daily steps adjusting for possible confounding variables.

Table 5 The independent variables influencing daily steps in the COPD

\begin{tabular}{llll}
\hline Variables & $\boldsymbol{\beta}$ & $\boldsymbol{t}$-value & $\boldsymbol{P}$-value \\
\hline OLST & 0.705 & 4.666 & $<0.001$ \\
6MWD & 0.339 & 1.729 & 0.103 \\
MMRC & -0.041 & -0.211 & 0.836 \\
QMVC & 0.077 & 0.527 & 0.605 \\
Adjusted $R^{2}$ & 0.731 & & \\
\hline
\end{tabular}

Note: This table shows the results of multivariable regression Analysis 2 using daily steps as the dependent variable and the OLST times, MMRC, QMVC, and 6MWD as predictors.

Abbreviations: OLST, one-leg standing test; $\beta$, standardized partial regression coefficient; adjusted $R^{2}$, adjusted coefficient of determination;6MWD, 6-minute walk distance; MMRC, modified Medical Research Council; QMVC, quadriceps isometric maximum voluntary contraction normalized to body weight. 
Table 6 The independent variables influencing MV-PA in the COPD patients $(n=22)$

\begin{tabular}{llll}
\hline Variables & $\boldsymbol{\beta}$ & $\boldsymbol{t}$-value & $\boldsymbol{P}$-value \\
\hline OLST & 0.519 & 2.743 & 0.014 \\
6MWD & 0.645 & 2.471 & 0.024 \\
MMRC & 0.183 & 0.753 & 0.462 \\
Adjusted $R^{2}$ & 0.518 & &
\end{tabular}

Note: This table shows the results of multivariable regression Analysis 3 using MV-PA as the dependent variable and the OLST times, MMRC, and 6MWD as predictors.

Abbreviations: $\beta$, standardized partial regression coefficient; adjusted $R^{2}$, adjusted coefficient of determination; MV-PA, time spent in moderate-to-vigorous physical activity per day; OLST, one-leg standing test; 6MWD, 6-minute walk distance; MMRC, modified Medical Research Council.

We observed that our COPD patients had deficits in anticipatory adjustments, gait stability, and transitions compared to the healthy controls. Nonsignificant reductions in standing balance were observed in the COPD group. It is difficult to directly compare our results with those of previous studies because the characteristics of the study subjects differed. However, the present differences in OLST times ( -16.0 seconds) and SPPB total scores ( -1.3 points) exceeded the previously reported differences in both measurements between COPD and healthy controls $\left(-13.4\right.$ seconds $^{31}$ and -1.0 points, ${ }^{32}$ respectively). Deficits in the 4MGS $\left(-0.49 \mathrm{~m} \cdot \mathrm{s}^{-1}\right)$ and $5 \mathrm{STST}$ times (3.30 seconds) also exceeded the minimal clinically important thresholds previously identified for these measures in COPD $\left(0.11 \mathrm{~m} \cdot \mathrm{s}^{-1}, 3^{33}\right.$ and $1.7 \mathrm{~seconds},{ }^{34}$ respectively $)$. In contrast, our COPD patients showed a nonsignificant difference in the standing balance test scores.

A possible explanation for these results may be that the ability to maintain a calm standing position is less likely to be impaired in COPD. Kawagoshi et $a l^{35}$ revealed that ambulatory COPD patients had similar values of daily time spent standing compared to age-matched healthy controls, ${ }^{35}$ which suggests that standing balance may be maintained in ambulatory COPD patients. In the present study, all of the COPD patients were able to walk without any supports, and they might spend enough time standing each day to maintain their standing balance. Thus, there were no significant differences in standing balance test scores between our COPD and control groups.

Our COPD patients showed reduced physical activity. The mean of their daily steps was 4,546 steps per day, which is lower than a step-defined sedentary lifestyle threshold $(5,000$ steps per day $)^{36}$ in adults and the mean number of daily steps $(5,876$ steps per day) that was demonstrated in COPD patients with similar ages and disease severity. ${ }^{37}$ The present deficits in daily steps compared to the healthy controls $(-4,167$ steps per day) also exceeded a clinically important difference for daily steps in older adults (2,000 steps per day). ${ }^{38}$ We also observed that the MV-PA was significantly reduced in our COPD patients. The mean MV-PA in the COPD group was 13.9 min. day $^{-1}$, which is approximately one-half as long as that of the control group $\left(27.4 \mathrm{~min} \cdot \mathrm{day}^{-1}\right)$. The mean was also lower than a recommended level of physical activity for adults $^{11}$ (30 minutes of at least moderate intensity physical activity on 5 or more days every week). These results are consistent with previous studies and emphasize that individuals with COPD have impaired balance and reduced physical activity levels compared to healthy controls.

In our study, physical activity (daily steps and MV-PA), exercise capacity, muscle strength, and dyspnea were associated with balance. Only physical activity had an independent relationship with balance in COPD after adjusting for possible confounding variables. Although a relationship between self-reported physical activity and balance has been shown, ${ }^{9}$ the present study is the first to explore the relationship between balance and physical activity measured by an activity monitor in this patient population. Our finding of an association between balance and physical activity was consistent with previous results. ${ }^{9}$ The correlation between balance and physical activity in the present study (OLST $r=0.821$; SPPB total $-r=0.563$ ) exceeded that in the previous study $(r=0.040){ }^{9}$

The relationship between balance and physical activity has been less studied. Some research groups suggest that sedentary older adults have less postural control than their more active peers. ${ }^{39}$ Kawagoshi et $\mathrm{al}^{35}$ reported that time spent at slow walking $\left(<2 \mathrm{~km} \cdot \mathrm{h}^{-1}\right)$, fast walking $\left(>2 \mathrm{~km} \cdot \mathrm{h}^{-1}\right)$, and the frequency of standing up were significantly lower in COPD patients compared to healthy controls. ${ }^{35}$ That study suggests that COPD patients may have reduced physical activity that requires anticipatory adjustments, gait stability, and transitions such as slow and fast walking, standing up from a chair, and climbing and descending stairs. In the present study, the COPD patients had significant lower numbers of daily steps and shorter MV-PA, and thus we also observed that the physical activity requiring dynamic balance might be also reduced in COPD. Such a sedentary lifestyle may lead to deterioration in balance.

Muscle weakness is a well-established risk factor for impaired balance in individuals in COPD. ${ }^{9}$ Exercise intolerance may be associated with balance in COPD..$^{40}$ Dyspnea may also be related to balance in COPD populations. ${ }^{10}$ In a previous study, "fallers" with COPD had significantly greater reductions in CRQ dyspnea scores compared to non-fallers with COPD. ${ }^{10}$ Based on our present findings and those of 
previous studies, reduced physical activity in COPD may contribute to impairments in balance independent of some possible confounding factors, such as loss of muscle strength, exercise intolerance, and dyspnea.

In the present study, balance, exercise capacity, lower muscle strength, and dyspnea were associated with the number of daily steps. Only balance was independently associated with daily steps in the COPD patients after the adjustment for possible confounding variables. Balance, exercise capacity, and dyspnea were also associated with MV-PA. Balance and exercise capacity had independent associations with MV-PA in our COPD group.

These results are consistent with those of previous studies, ${ }^{7,8}$ and they emphasize that balance impairments lead to reductions in physical activity in COPD patients. Deficits in balance are well-established predictors of activity limitations such as walking around the house and sitting/standing transferring among elderly people. ${ }^{16,41}$ Shorter OLST times, for example, have been shown to be a marker of activity limitations in elderly people. ${ }^{16}$ Poor performance in walking and rising from a sitting position has a good predictive value of activity limitations in elderly people. ${ }^{41}$ Durutürk and Tonga ${ }^{42}$ investigated the relationship between balance and activity limitations assessed by the London Chest Activities of Daily Living (LCADL) scale in COPD. ${ }^{42}$ The scale consists of four subcomponents of activities of daily livings: self-care activities, household activities, transitional activities, and leisure time activities. ${ }^{43}$ Deficits in balance were significantly associated with LCADL household activities and leisure time activities. ${ }^{42}$ COPD patients with balance impairments may thus choose a sedentary lifestyle in order to prevent falls while engaging in activities of daily livings.

Exercise intolerance, ${ }^{8}$ muscle weakness, ${ }^{7}$ and dyspnea ${ }^{8}$ have also been shown to affect physical activity in COPD. In the present study, exercise capacity measured by the 6MWD test had an independent association with MV-PA, but not with daily steps. Additionally, the association of 6WMD with MV-PA ( $\beta=0.645)$ was greater than that with daily steps $(\beta=0.339)$. These results are consistent with those of a previous study. ${ }^{44}$ That study investigated the relationships between self-reported physical activity and 6MWD in COPD patients, and the results indicated that time spent in high physical activity per week was more strongly associated with 6MWD than light physical activity. ${ }^{44}$ These findings suggest that in COPD, exercise capacity may have a greater impact on the intensity of physical activity compared to the total amount of physical activity. The results of the present study and those of the previous studies suggest that balance impairments may also lead to a sedentary lifestyle independently of some confounding factors in COPD.

Here we showed a possible bidirectional association between balance and physical activity in COPD, which indicates that deficits in balance and physical inactivity may affect each other. Beauchamp et $\mathrm{al}^{45}$ reported that a standardized 6-week multidisciplinary pulmonary rehabilitation (PR) program contributed to minor improvements in balance in COPD patients. They suggested that balance training should be included in a PR program to improve balance. ${ }^{45}$ Our present findings emphasize the importance of balance training in PR for improving not only balance but also the level of physical activity, especially in COPD patients with impaired balance.

Certain limitations must be taken into consideration when interpreting our results. Because the design of this study was cross-sectional, the causality or directionality of the findings is uncertain. Because the sample size was small for a regression analysis with five predictors to achieve sufficient statistical power, larger prospective studies are required to establish the relationship between balance and objectively measured physical activity in COPD.

\section{Conclusion}

In summary, we note that our patients with COPD had reduced performance in three subcomponents of balance (anticipatory adjustments, walking stability, and transitions) and lower physical activity (daily steps and MV-PA) compared to agematched healthy control subjects. There was an independent association between impaired balance and low number of daily steps after adjusting for possible confounding factors. In light of the present and previous findings, ${ }^{9}$ a balance evaluation should be conducted to assess not only the risk of falling but also the causes of physical inactivity, especially in elderly COPD patients who are at risk of falling and/or have reduced physical activity. There is a clear need for further research to clarify the causal direction between balance and physical activity in people with COPD.

\section{Acknowledgments}

The authors acknowledge the members of the Department of Rehabilitation at Akita City Hospital (C Kasai, N Kiyokawa, T Watanabe, Y Ishikawa, and M Oshima) for their assistance in data collection.

\section{Disclosure}

The authors report no conflicts of interest in this work. 


\section{References}

1. Watz H, Waschki B, Meyer T, Magnussen H. Physical activity in patients with COPD. Eur Respir J. 2009;33:262-272.

2. Pitta F, Troosters T, Spruit MA, Probst VS, Decramer M, Gosselink R. Characteristics of physical activities in daily life in chronic obstructive pulmonary disease. Am J Respir Crit Care Med. 2005;171:972-977.

3. Vorrink SN, Kort HS, Troosters T, Lammers JW. Level of daily physical activity in individuals with COPD compared with healthy controls. Respir Res. 2011;12:33.

4. Garcia-Aymerich J, Lange P, Serra I, Schnohr P, Antó JM. Timedependent confounding in the study of the effects of regular physical activity in chronic obstructive pulmonary disease: an application of the marginal structural model. Ann Epidemiol. 2008;18(10):775-783.

5. Waschki B, Kirsten AM, Holz O, et al. Disease progression and changes in physical activity in patients with chronic obstructive pulmonary disease. Am J Respir Crit Care Med. 2015;192(3):295-306.

6. Vaes AW, Garcia-Aymerich J, Marott JL, et al. Changes in physical activity and all-cause mortality in COPD. Eur Respir J. 2014;44(5): 1199-1209.

7. Osthoff AK, Taeymans J, Kool J, Marcar V, van Gestel AJ. Association between peripheral muscle strength and daily physical activity in patients with COPD: a systematic literature review and meta-analysis. J Cardiopulm Rehabil Prev. 2013;33(6):351-359.

8. Gimeno-Santos E, Frei A, Steurer-Stey C, et al. Determinants and outcomes of physical activity in patients with COPD: a systematic review. Thorax. 2014;69(8):731-739.

9. Beauchamp MK, Sibley KM, Lakhani B, et al. Impairments in systems underlying control of balance in COPD. Chest. 2012;141:1496-1503.

10. Roig M, Eng JJ, MacIntyre DL, et al. Falls in people with chronic obstructive pulmonary disease: an observational cohort study. Respir Med. 2010;105:461-469.

11. Watz H, Pitta F, Rochester CL, et al. An official European Respiratory Society statement on physical activity in COPD. Eur Respir J. 2014; 44(6):1521-1537.

12. Porto EF, Castro AA, Schmidt VG, et al. Postural control in chronic obstructive pulmonary disease: a systematic review. Int $J$ Chron Obstruct Pulmon Dis. 2015;10:1233-1239.

13. Caspersen CJ, Powell KE, Christenson GM. Physical activity, exercise, and physical fitness: definitions and distinctions for health-related research. Public Health Rep. 1985;100:126-131.

14. Howley ET. Type of activity: resistance, aerobic and leisure versus occupational physical activity. Med Sci Sports Exerc. 2001;33(Supp 1): S364-S369.

15. Vestbo J, Hurd SS, Agustí AG, et al. Global strategy for the diagnosis, management, and prevention of chronic obstructive pulmonary disease: GOLD executive summary. Am J Respir Crit Care Med. 2013;187(4): 347-365.

16. Michikawa T, Nishiwaki Y, Takebayashi T, Toyama Y. One-leg standing test for elderly population. J Orthop Sci. 2009;14:675-685.

17. Guralnik JM, Simonsick EM, Ferrucci L, et al. A short physical performance battery assessing lower extremity function: association with self-reported disability and prediction of mortality and nursing home admission. J Gerontol. 1994;49:85-94.

18. Bisca GW, Morita AA, Hernandes NA, Probst VS, Pitta F. Simple lower limb function tests in patients with chronic obstructive pulmonary disease: a systematic review. Arch Phys Med Rehab. 2015;96(12):2221-2230.

19. Muehlbauer T, Gollhofer A, Granacher U. Associations between measures of balance and lower-extremity muscle strength/power in healthy individuals across the lifespan: a systematic review and meta-analysis. Sports Med. 2015;45(12):1671-1692.

20. Whitney SL, Wrisley DM, Marchetti GF, Gee MA, Redfern MS, Furman JM. Clinical measurement of sit-to-stand performance in people with balance disorders: validity of data for the five-times-sit-to-stand test. Phys Ther. 2005;85:1034-1035.

21. United States Department of Health and Human Services. 2008 Physical Activity Guidelines for Americans: Be Active, Healthy, and Happy! Washington, DC: United States Department of Health and Human Services; 2008.
22. Schneider PL, Crouter SE, Lukajic O, Bassett DR Jr. Accuracy and reliability of 10 pedometers for measuring steps over a $400-\mathrm{m}$ walk. Med Sci Sports Exerc. 2003;35:1779-1784.

23. Kumahara H, Schutz Y, Ayabe M, et al. The use of uniaxial accelerometry for the assessment of physical-activity-related energy expenditure: a validation study against whole-body indirect calorimetry. Br J Nutr. 2004;91(2):235-243.

24. American Thoracic Society. Standardization of spirometry - 1987 update. Statement of the American Thoracic Society. Am Rev Respir Dis. 1987;136:1285-1298.

25. Berglund E, Birath G, Bjure J, et al. Spirometric studies in normal subjects. I. Forced expirograms in subjects between 7-70 years of age. Acta Med Scand. 1963;173:185-192.

26. Mahler D, Wells C. Evaluation of clinical methods for rating dyspnea. Chest. 1988;93:580-586.

27. Sugawara K, Takahashi H, Kashiwagura T, et al. Effect of antiinflammatory supplementation with whey peptide and exercise therapy in patients with COPD. Respir Med. 2012;106: $1526-1534$.

28. Holland AE, Spruit MA, Troosters T, et al. An official European Respiratory Society/American Thoracic Society technical standard: field walking tests in chronic respiratory disease. Eur Respir J. 2014;44: $1428-1446$.

29. Jones PW, Harding G, Berry P, Wiklund I, Chen WH, Kline Leidy N. Development and first validation of the COPD Assessment Test. Eur Respir J. 2009;34(3):648-654.

30. Faul F, Erdfelder E, Buchner A, Lang AG. Statistical power analyses using $\mathrm{G}^{*}$ Power 3.1: tests for correlation and regression analyses. Behav Res Methods. 2009;41(4):1149-1160.

31. Crişan AF, Oancea C, Timar B, Fira-Mladinescu O, Tudorache V. Balance impairment in patients with COPD. PLoS One. 2015;10(3): e0120573.

32. Eisner MD, Blanc PD, Yelin EH, et al. COPD as a systemic disease: impact on physical functional limitations. Am J Med. 2008;121(9): 789-796.

33. Kon SS, Canavan JL, Nolan CM, et al. The 4-metre gait speed in COPD: responsiveness and minimal clinically important difference. Eur Respir J. 2014;43(5):1298-1305.

34. Jones SE, Kon SS, Canavan JL, et al. The five-repetition sit-to-stand test as a functional outcome measure in COPD. Thorax. 2013;68(11): $1015-1020$

35. Kawagoshi A, Kiyokawa N, Sugawara K, et al. Quantitative assessment of walking time and postural change in patients with COPD using a new triaxial accelerometer system. Int J Chron Obstruct Pulmon Dis. 2013;8:397-404

36. Tudor-Locke C, Craig CL, Thyfault JP, Spence JC. A step-defined sedentary lifestyle index: $<5000$ steps/day. Appl Physiol Nutr Metab. 2013;38(2):100-114.

37. Donaire-Gonzalez D, Gimeno-Santos E, Balcells E, et al. Physical activity in COPD patients: patterns and bouts. Eur Respir J. 2013;42: 993-1002.

38. Aoyagi Y, Shephard RJ. Habitual physical activity and health in the elderly: the Nakanojo Study. Geriatr Gerontol Int. 2010;10(Suppl 1): S236-S243.

39. Prioli AC, Freitas Júnior PB, Barela JA. Physical activity and postural control in the elderly: coupling between visual information and body sway. Gerontology. 2005;51(3):145-148.

40. Beauchamp MK, Brooks D, Goldstein RS. Deficits in postural control in individuals with COPD - emerging evidence for an important secondary impairment. Multidiscip Respir Med. 2010;5(6): $417-421$.

41. Vermeulen J, Neyens JC, van Rossum E, Spreeuwenberg MD, de Witte LP. Predicting ADL disability in community-dwelling elderly people using physical frailty indicators: a systematic review. $B M C$ Geriatr. 2011;11:33.

42. Durutürk N, Tonga E. The association among balance, activity limitation, dyspnea and vulnerability in chronic obstructive pulmonary diseases. Eur Respir J. 2013;42(Suppl 57):P1298. 
43. Garrod R, Bestall JC, Paul EA, Wedzicha JA, Jones PW. Development and validation of a standardized measure of activity of daily living in patients with severe COPD: the London Chest Activity of Daily Living scale (LCADL). Respir Med. 2000;94(6):589-596.

44. Frisk B, Espehaug B, Hardie JA, et al. Physical activity and longitudinal change in 6-min walk distance in COPD patients. Respir Med. 2014; 108(1):86-94.
45. Beauchamp MK, O’Hoski S, Goldstein RS, Brooks D. Effect of pulmonary rehabilitation on balance in persons with chronic obstructive pulmonary disease. Arch Phys Med Rehabil. 2010;91:1460-1465.

\section{Publish your work in this journal}

The International Journal of COPD is an international, peer-reviewed journal of therapeutics and pharmacology focusing on concise rapid reporting of clinical studies and reviews in COPD. Special focus is given to the pathophysiological processes underlying the disease, intervention programs, patient focused education, and self management protocols.
This journal is indexed on PubMed Central, MedLine and CAS. The manuscript management system is completely online and includes a very quick and fair peer-review system, which is all easy to use. Visit http://www.dovepress.com/testimonials.php to read real quotes from published authors. 